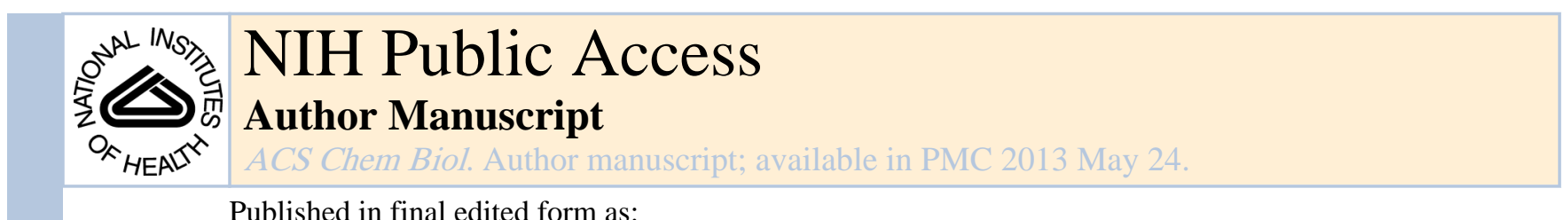

ACS Chem Biol. 2012 October 19; 7(10): 1746-1753. doi:10.1021/cb300329r.

\title{
Selective Penicillin-Binding Protein Imaging Probes Reveal Substructure in Bacterial Cell Division
}

\author{
Ozden Kocaoglu†, Rebecca A. Calvo§, Lok-To Sham§, Loralyn M. Cozy§,\#, Bryan R. \\ Lanning $^{\ddagger}, \#$, Samson Francis ${ }^{\ddagger}$, Malcolm E. Winkler ${ }^{\S}$, Daniel B. Kearns ${ }^{\S}$, and Erin E. \\ Carlson,$+ \neq, *$ \\ ¥Department of Chemistry, Indiana University, Bloomington, IN 47405, USA \\ tDepartment of Molecular and Cellular Biochemistry, Indiana University, Bloomington, IN 47405, \\ USA
}

§Department of Biology, Indiana University, Bloomington, IN 47405, USA

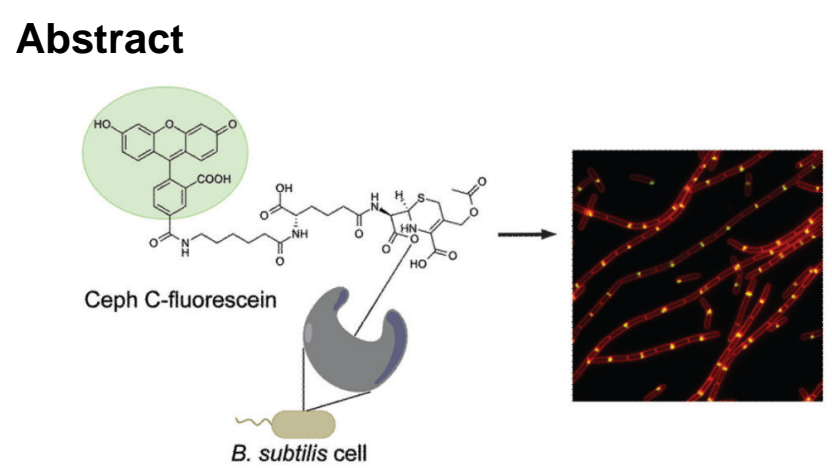

The peptidoglycan cell wall is a common target for antibiotic therapy but its structure and assembly are only partially understood. Peptidoglycan synthesis requires a suite of penicillinbinding proteins (PBPs), the individual roles of which are difficult to determine because each enzyme is often dispensable for growth perhaps due to functional redundancy. To address this challenge, we sought to generate tools that would enable selective examination of a subset of PBPs. We designed and synthesized fluorescent and biotin derivatives of the $\beta$-lactam-containing antibiotic cephalosporin $C$. These probes facilitated specific in vivo labeling of active PBPs in both Bacillus subtilis PY79 and an unencapsulated derivative of D39 Streptococcus pneumoniae. Microscopy and gel-based analysis indicated that the cephalosporin C-based probes are more selective than BOCILLIN-FL, a commercially available penicillin $\mathrm{V}$ analog, which labels all PBPs. Dual labeling of live cells performed by saturation of cephalosporin C-susceptible PBPs followed by tagging of the remaining PBP population with BOCILLIN-FL demonstrated that the two sets of PBPs are not co-localized. This suggests that even PBPs that are located at a particular site (e.g., septum) are not all intermixed, but rather that PBP subpopulations are discretely localized. Accordingly, the Ceph C probes represent new tools to explore a subset of PBPs and have the potential to facilitate a deeper understand of the roles of this critical class of proteins.

\footnotetext{
*Corresponding Author carlsone@indiana.edu.

\#These authors contributed equally to this work.

Supporting Information

The synthesis and characterization of Ceph C-based probes, detailed descriptions of experimental procedures and additional data. This material is available free of charge via the Internet at http://pubs.acs.org.
} 
Most bacteria are surrounded by a cell wall composed of a complex polymeric structure called peptidoglycan (PG) that is essential for cell survival.(1) The biosynthetic pathway for production of PG and the proteins required for its assembly have been the targets for many antibacterial agents.(2) For example, penicillin-binding proteins (PBPs), which polymerize and crosslink strands of PG (Figure 1, panel a) also have affinity for the $\beta$-lactam antibiotic penicillin (Figure 1, panel b). $(3,4)$ PBPs are classified into three groups based upon their molecular weight and conserved amino acid motifs: class A and class B high molecular weight (HMW) PBPs and low molecular weight (LMW) PBPs. Class A HMW PBPs have an $\mathrm{N}$-terminal domain which possesses glycosyltransferase activity and a $\mathrm{C}$-terminal domain that performs transpeptidation. Class B HMW PBPs have C-terminal transpeptidase activity and unknown N-terminal functions. LMW PBPs commonly have D,D-carboxypeptidase activity and play a major role in regulating cross-linking between glycan chains.(5) These proteins all contain a serine in their peptidase domain that is required for catalysis (Figure 1, panel a). Penicillin potentiates PBP function by forming a stable acyl-enzyme intermediate with this residue, which in turn inhibits crosslinking of PG (Figure 1, panel c). Despite the effectiveness of $\beta$-lactam antibiotics, bacterial resistance has arisen very rapidly. $(6,7) \mathrm{A}$ better and more detailed understanding of the mechanism of PG synthesis may be the key for design of new and more effective antibiotics.

Since the elucidation of penicillin's mechanism of action, it has been used as a probe to gain more insight into bacterial physiology. $(8,9)$ A standard strategy for detection of PBP activity is tagging with a radiolabeled $\beta$-lactam, such as penicillin, and subsequent separation by sodium dodecyl sulfate-polyacrylamide gel electrophoresis (SDS-PAGE) and detection by fluorography.(10) Although this method is well-established, radiolabeled $\beta$ lactam molecules are hazardous making them non-ideal to handle for routine or large-scale analysis. Furthermore, the experimental procedure is time consuming taking up to several days and most importantly, it cannot be used for in vivo visualization of PBPs. Fluorescent labeling has become a very useful tool for the monitoring of proteins in their native environment. Green fluorescent protein (GFP) is a well-known example that has been used to study protein expression and localization in living systems but requires genetic manipulation of each protein of interest and artificial fusions can disturb protein localization, function, and levels. $(11,12)$ Fluorescently labeled small molecule probes can be used to overcome the disadvantages of both radioactivity- and protein fusion-based strategies with the additional benefit of directly detecting the activity state of the target.

Small molecule-conjugated fluorophores that label their protein targets in an activitydependent fashion can provide superior temporal resolution and their activity can be modulated by dose.(13) These compounds are also generally easy to use and enable visualization in a broad range of organisms. Fluorophore-conjugated vancomycin and ramoplanin have been generated and used to label PG biosynthetic precursors in various Gram-positive bacteria to reveal the sites of new PG synthesis in these organisms.(14, 15) Besides radiolabeled penicillin, fluorophore-conjugated variants such as BOCILLINFL (Boc-FL), which is commercially available, have been developed to visualize bacterial $\operatorname{PBPs}(16,17)$ and peptidoglycan biosynthetic machinery in living cells. Although Boc-FL has been an important research tool, it visualizes all PBPs at once abrogating the possibility of exploring the function of only one or several PBPs. Accordingly, we sought to generate tools that would enable selective examination of a subset of PBPs in vivo.

We anticipated that PBP selective probes could be obtained by derivatization of an antibiotic known to target only the desired PBPs. In 2008, Staub et al. synthesized a library of antibiotic-based chemical probes that included cephalosporin, aztreonam, and ampicillin analogs to tag catalytically active PBPs in Pseudomonas putida, Listeria welshimeri, and Bacillus licheniformis. Bacterial proteomes were labeled with these activity-based probes 
followed by attachment of a fluorophore tag (via click chemistry) and visualized using fluorescence gel scanning. $(18,19)$ Each compound labeled a different set of PBPs in the three organisms due to the structural differences between the three antibiotic-inspired probes.(20) We sought to combine the ideas of utilizing a fluorescently-labeled antibiotic with the use of a selective scaffold that interacts with only a subset of PBPs to generate probes that could readily visualize the activity of specific PBP in live cells. Accordingly, we synthesized a set of probes based upon the antibiotic cephalosporin $\mathrm{C}$ and applied them to the study of both Bacillus subtilis and Streptococcus pneumoniae.

\section{RESULTS AND DISCUSSION}

It is well established that many HMW PBPs, the proteins that facilitate peptidoglycan polymerization and incorporation into existing cell wall structures, are sensitive to cephalosporin antibiotics making generation of probes based upon this scaffold an attractive target. $(21,22)$ Cephalosporin-fluorophore conjugates have previously been utilized for FRET-based detection of $\beta$-lactamase activity but have not been used for microscopic visualization.(23) We designed and synthesized fluorescent cephalosporin C (Ceph C) molecules to selectively label PBPs and monitor their localization in living bacterial cells. These probes were used for the visualization and identification of PBPs with three different techniques, protein gel electrophoresis, microscopy, and liquid chromatography-mass spectrometry (LC-MS), and contained one of three reporter tags, carboxytetramethylrhodamine (TAMRA; Ceph C-T), carboxyfluorescein (Ceph C-F), or biotin (Ceph C-B; Figure 2, panel a).

To verify that the functionalized Ceph $\mathrm{C}$ analogs selectively label the anticipated HMW PBPs, gel-based analysis was performed using $B$. subtilis PY79 cells. First, experiments to assess the minimal inhibitory concentration of Ceph C (Supplementary Figure 1) and viability over time (Supplementary Figure 2) established that $B$. subtilis cells could be treated with concentrations of $\leq 10 \mathrm{~g} / \mathrm{mL}$ for periods of less than one hour without significant cell damage. Accordingly, these conditions were utilized in all future experiments. Gels obtained following labeling with Ceph C-T or Boc-FL are depicted in Figure 2, panel b. Interestingly, in vivo labeling and in vitro labeling of the membrane proteome with Ceph C-T resulted in somewhat different profiles in the PBP2 region (Figure 2, panel b; Supplementary Figure 3). Based upon comparison to the Boc-FL gel it appears that PBP2a, $2 \mathrm{~b}$ and $2 \mathrm{c}$ are labeled in vitro while only $2 \mathrm{~b}$ and $2 \mathrm{c}$ label in vivo, with the staining of the later being intensified under these conditions. This may indicate differences in either accessibility of the proteins to the probe in whole cells and/or changes in PBP activity upon cell lysis. In vivo labeling with Ceph C-F produced a similar profile to Ceph $\mathrm{C}-\mathrm{T}$, but use of this probe in gel-based analysis was not optimal given the propensity of this fluorophore to photobleach (data not shown). Pretreatment with unlabeled Ceph C prevented fluorescent labeling by competition (Supplementary Figure 4). We infer that the fluorescently labeled and unlabeled Ceph $\mathrm{C}$ bind to the same subset of proteins.

While comparison with the Boc-FL gel, whose protein content was previously assigned,(24) enabled speculation about the proteins labeled with Ceph C-T, we employed Ceph C-B to confirm their identities. B. subtilis PY79 membrane proteome was incubated with this probe and the biotinylated proteins were enriched using a streptavidin-functionalized matrix. The enriched proteins were subjected to proteolytic cleavage by trypsin and the resulting peptides analyzed by LC-MS/MS (ESI-LCQ Deca XP Plus). The obtained data were searched against the $B$. subtilis FASTA amino acid sequence database using the Mascot algorithm (Matrix Science; Supplementary Table 2). The MS identifications revealed that Ceph C-B labels the anticipated HMW PBPs in B. subtilis, PBPs 1a/1b, 2a, 2b and 4 (Figure 2 , panel $b$ ), several of which are known to promote cell elongation and cell division of this 
bacterium.(24) Given this information and the assignments from previous work in Boc-FL, we can infer that the final band is PBP2c. This protein was observed in one data set by mass spectral analysis but could not be unambiguously validated using this strategy likely because this PBP is poorly labeled under in vitro conditions (Figure 2, panel b) and is known to be a very low abundance protein.(22)

With the selectivity of the Ceph C-based probes established, we pursued microscopy studies aimed at visualizing PBP localization in $B$. subtilis PY79. Cells were grown to midlog phase, labeled with Ceph C-F and then stained with N-(3-triethylammoniumpropyl)-4-(6-(4(diethylamino)phenyl) hexatrienyl)pyridinium dibromide (FM-4-64) to visualize membranes (Figure 3). The images revealed that Ceph C-F labels every other septum in a chain of cells suggesting that the probe interacts only with the PBPs that are localized at the site of active septal PG synthesis. As before, pretreatment with unlabeled Ceph $\mathrm{C}$ resulted in preclusion of staining with the Ceph C-fluorophore conjugates (Supplementary Figure 5). The observed labeling pattern is consistent with what has been noted with GFP fusion and immunofluorescence techniques in that PBP1a/1b and $2 \mathrm{~b}$ showed septal localization.(12, 25). The previously generated GFP-PBP2c and 4 localization data were inconclusive due to processing of the fusion protein.(12) The Ceph $\mathrm{C}$ probes yielded similar localization patterns to those seen with Boc-FL (Figure 3). This was expected given that previously reported GFP fusion studies indicate that the highly abundant PBP5 is localized at both the septum and along the lateral wall and PBP2a is also found at the septa.(12) PBP3 is generally not localized at the septa, but instead shows peripheral staining. Fluorescence of the side wall was faint when labeled with either Ceph C-F or Boc-FL.

We also sought to determine the localization of the labeled PBPs relative to ZapA (FtsZ rings). Cells containing a yellow fluorescent protein (YFP) fused to the C-terminus of ZapA (ZapA-YFP)(26) were stained with Ceph C-T, unlabeled Ceph C or TAMRA dye. When treated with either unlabeled Ceph $\mathrm{C}$ or TAMRA dye, the Z-ring localized to the midcell normally (Supplementary Figure 6). However, when exposed to Ceph C-T the septal localization appeared to be disrupted and ZapA primarily localized to the cytoplasm as a diffuse haze. We infer that inhibition of the PBPs alone by treatment with an antibiotic (i.e., unlabeled Ceph C) does not affect Z-ring formation, but that the added bulk of the fluorophore present on Ceph C-T may prevent critical interactions between the PBPs and other cellular components leading to Z-ring disruption. Intriguingly, this would potentially require that the PBPs communicate from outside the cell to affect FtsZ ring placement inside the cell. Consistent with outside-in interference of cytoskeletal elements, we note that extracellular inhibition with cell wall disrupting antibiotics has recently been demonstrated to interrupt dynamics of the cytoplasmic MreB cytoskeletal element in B. subtilis. $(27,28)$

With these new tools in hand, we next sought to determine if we could combine the use of Ceph C-T and Boc-FL to visualize the two subpopulations of PBPs in a single cell. Ceph Csusceptible PBPs were first saturated by incubation with Ceph $\mathrm{C}-\mathrm{T}$ and then the remaining PBPs were labeled with Boc-FL. Gel-based analysis showed that sequential labeling resulted in retention of the specificity seen in single labeling experiments and that Ceph C-T labeling saturation was achieved (Figure 4, panel a and Supplementary Figure 7). As expected, PBPs 1a/1b, 2b, 2c and 4 were stained with Ceph C-T and PBPs 2a, 3 and 5 were labeled with Boc-FL.

Wide-field images of $B$. subtilis obtained after dual labeling showed co-localization of both dyes at the septa (Figure 4, panel b), which is consistent with the images seen after treatment with a single compound. However, examination of these cells using super-resolution microscopy (3D-SIM) yielded greater detail. At this resolution, unique septal labeling patterns were observed between the two PBP subsets (Figure 5; PBPs 1a/1b, 2b, 2c and 4 in 
red, PBPs 2a, 3 and 5 in green and chromophore overlap appears yellow). Our experiments were performed on non-synchronized populations of cells and we hypothesize that the localization patterns varied depending upon the divisional status of the cell (> 95\% of the observed cells stained as described). Cells with the earliest divisional septa, as indicated by the absence of membrane invaginations, showed crescent-shaped fluorescent labeling with asymmetric intensity (Figure 5, panel a). In the next stage, marked by invaginations of the membrane, the fluorescence localized as a disk that bisected the parent cell with Boc-FL tagged PBPs (likely PBP5 since PBP2a and 3 are known to stain peripherally) on the exterior and Ceph C-labeled PBPs on the interior (Figure 5, panel b). Following division, indicated by a complete staining of the septum with membrane stain, crescent shapes were retained at the pole of each daughter cell (Figure 5, panel c). Collectively, these data indicate that septally localized PBPs may be interspersed, but that PBP subpopulations are differentially activated about the septa depending upon the divisional status of the cell. PBP activating proteins have recently been identified in E. coli and dynamic activation by hypothetical PBP activators in $B$. subtilis could account for the complex activity we observe at the septum. $(29,30)$

Control experiments to examine the super-resolution fluorescence staining patterns of Ceph C-T alone, Boc-FL alone, unlabeled Ceph C followed by Boc-FL or Boc-FL followed by Ceph C-T were also performed (Supplementary Figure 8). As anticipated, labeling with only Boc-FL resulted in full septal staining while pretreatment with nonfluorescent Ceph C followed by Boc-FL resulted in a partial disk with no labeling in the center indicating saturation of the Ceph C susceptible PBPs. Additionally, sequential staining first with BocFL and then Ceph C-T yielded cells stained only with the former compound again indicating saturation with the utilized dye concentration. Additional control experiments showed that dual-labeling patterns were not affected when cells were labeled in growth medium instead of being suspended in phopshate-buffered saline and imaged using a $2 \%$ agarose pad and plain cover slips instead of slides coated with poly-lysine (data not shown).

To demonstrate the generality of the devised probes, we also employed them in the visualization of PBPs in live Streptococcus pneumoniae IU1945, an unencapsulated derivative of strain D39.(31) Both Ceph C-T and Boc-FL were applied to wild type cells and a collection of PBP mutants and assessed in our gel-based assay (Figure 6, panel a). In single labeling experiments, Ceph C-T preferentially labels PBPs $1 \mathrm{~b}$ and 3, with a minimal amount of staining of PBP1a, whereas Boc-FL labels all PBPs. In S. pneumoniae, PBPs 1a, $1 \mathrm{~b}$, and 2a are Class A, PBPs $2 \mathrm{~b}$ and $2 \mathrm{x}$ are Class B, and PBP3 (DacA) is a low molecular weight $\mathrm{PBP}$, which previously was shown to have affinity for certain cephalosporins.(3234) Pretreatment with unlabeled Ceph $C$ prevented fluorescent labeling by competition indicating that fluorescently labeled and unlabeled Ceph $\mathrm{C}$ bind to the same subset of proteins (Supplementary Figure 9). In addition, gel-based control experiments showed that in vivo labeling of $S$. pneumoniae cells with Ceph C-T and Boc-FL was saturated (Supplementary Figure 9). Single labeling of a set of mutants deficient in non-essential $\operatorname{PBPs}(34)$ confirmed the identities of the PBPs (Figure 6, panel a).(33, 34)

The probes were next utilized in conventional single-label fluorescence microscopy experiments (Figure 6, panel b). Ceph C-T or Boc-FL separately labeled the septal and equatorial regions of $S$. pneumoniae IU1945 cells. This labeling pattern was expected from previous work. In ellipsoid-shaped (ovococcus) cells, the equators of pre-divisional cells become the division septa, and the protein machines, which contain PBP1a and $1 \mathrm{~b}$ and other PBPs that synthesize peripheral (side-wall) and septal peptidoglycan, localize to the midcell regions of dividing $S$. pneumoniae cells.(33-36) In addition, both probes labeled the surface of the cells, consistent with their labeling of PBP3 (Figure 6, panel a), which is randomly distributed over the surfaces of $S$. pneumoniae cells. $(37,38)$ 
Dual labeling experiments were performed and gel-based analysis indicated that Ceph C-T labels only $1 \mathrm{~b}$ and 3 under these conditions (Figure 6, panel c). This pattern is consistent with the weak staining of PBP1a by Ceph C-T seen in the single probe experiment (Figure 6, panel a). PBP3 appears to co-stain with both probes; however, this staining will have little effect on septal or equatorial labeling patterns since this protein is not localized in these regions. $(37,38)$ Accordingly, any Ceph C-T septal or equatorial staining would be due largely to visualization of PBP1b. Dual labeled cells were imaged using both wide-field fluorescence microscopy and super-resolution microscopy. Separation of the two PBP populations is not obvious in the lower resolution images with nearly all labeled regions appearing yellow from overlap of the two fluorophores (Supplementary Figure 10). In contrast, at higher resolution, segregation of the protein subsets can be seen (Figure 7). Ceph $\mathrm{C}-\mathrm{T}$ and Boc-FL both label at the septal and equatorial regions, but surprisingly, comparatively little overlap of the stains is observed. Instead, extended punctal localization of the two protein subsets is detected. This labeling pattern is remarkably similar to what was seen in B. subtilis (Figure 5). These observations suggest that PBP activities are not uniform in the midcell regions of dividing $S$. pneumoniae and that different populations of PBPs may be active at discrete locations at different times during division. These labeling patterns are consistent with the emerging model that septal and peripheral peptidoglycan biosynthesis are catalyzed by two separate protein machines located at midcell.(33-36)

Control experiments to examine the super-resolution fluorescence staining patterns of Ceph $\mathrm{C}-\mathrm{T}$ alone, Boc-FL alone, unlabeled Ceph $\mathrm{C}$ followed by Boc-FL or Boc-FL followed by Ceph C-T were also performed (Supplementary Figure 11). Labeling with only Boc-FL yielded cells displaying staining in both the septal and equatorial areas as both punctate spots and incomplete rings around the equator. Labeling with Ceph C-T alone resulted in punctal staining throughout both regions. Sequential staining first with Boc-FL and then Ceph C-T yielded cells stained only with the former compound confirming labeling saturation. Additional control experiments showed that dual-labeling patterns were not affected when $S$. pneumoniae IU1945 cells were labeled in growth medium, instead of being suspended in phopshate-buffered saline or when cells were viewed on slides not coated with poly-lysine (data not shown).

In summary, by generation of Ceph C-based probes we have produced selective, timeefficient biochemical methods to study the roles of PBPs in live Gram-positive bacteria. We have shown that these probes label active PBPs during nascent PG synthesis at the divisional septa and enable selective visualization of a subset of PBPs, which the commercially available penicillin analog, Boc-FL, does not. Accordingly, the Ceph C-based probes represent new tools to tease apart the function of a limited number of PBPs and enable rapid and simple corroboration of results obtained with other methods such as GFP-PBP fusions or PBP mutants. Examination of dual labeled B. subtilis and $S$. pneumoniae revealed that subsets of PBPs are differentially localized within the same region of a cell and that staining is heterogeneous around the septa indicating that there are areas of non-uniform PBP activity. Work is ongoing to utilize the Ceph C-based probes to further explore PBP localization in both $B$. subtilis and $S$. pneumoniae and to generate probes with other selectivity profiles. Future work will also seek to address generation of probes with utility in Gram-negative organisms.

\section{METHODS}

The syntheses of Ceph C-F, Ceph C-T, and Ceph C-B, application of Ceph C-B, analysis by LC-MS/MS, generation of mutant strains and details for dual labeling experiments are described in the Supporting Information. 


\section{In vivo labeling of B. subtilis and S. pneumoniae PBPs with Ceph C-T and Boc-FL for gel- based analysis}

B. subtilis PY79 cells were grown in Luria-Bertani (LB) broth at $37^{\circ} \mathrm{C}$ to $\mathrm{OD}_{600} 0.4-0.5$. Cells from $1 \mathrm{~mL}$ of culture were harvested by centrifugation $(16,100 \times \mathrm{g}$ for $1 \mathrm{~min}$ at $\mathrm{RT})$ and washed with phosphate buffered saline (PBS; pH 7.4). Cell pellets were resuspended in $50 \mu \mathrm{L}$ of PBS containing $10 \mu \mathrm{g} \mathrm{mL}-1$ of Ceph C-T or $5 \mu \mathrm{g} \mathrm{mL}-1$ of Boc-FL (Molecular Probes). After incubation for $30 \mathrm{~min}$ with Ceph C-T or $10 \mathrm{~min}$ with Boc-FL at RT, the cells were washed and resuspended in $100 \mu \mathrm{L}$ of PBS containing $1 \mathrm{mg} \mathrm{mL}^{-1}$ of lysozyme and were incubated for $30 \mathrm{~min}$ at $37^{\circ} \mathrm{C}$. The cells were lysed by Branson Sonifier 250 (power setting $3,30 \%$ duty cycle for $5 \times 6$ s intervals) and membrane proteome was isolated by ultracentrifugation (Beckman Coulter Optima Max-XP Ultracentrifuge) at 100,000 $\times \mathrm{g}(1 \mathrm{~h})$, $4{ }^{\circ} \mathrm{C}$. Membrane proteome was resuspended in PBS and protein concentration was determined by NanoDrop 1000 Spectrophotometer (Thermo Scientific). Proteome sample was diluted to $2.5 \mathrm{mg} \mathrm{mL}^{-1}$ in PBS. Following the addition of $17 \mu \mathrm{L}$ of $4 \times$ SDS-PAGE loading buffer to $51 \mu \mathrm{L}$ of proteome, the sample was heated for $5 \mathrm{~min}$ at $90-95^{\circ} \mathrm{C}$, cooled to RT, run on a $10 \%$ SDS-PAGE and labeled proteins were visualized in gel using a Typhoon 9210 gel scanner (Amersham Biosciences). All gel images were analyzed using ImageJ software (NIH).

S. pneumoniae IU1945, E177 ( $\Delta$ pbp1a), E193 ( $\Delta$ pbp1b), E180 ( $\Delta$ pbp2a), IU5080 ( $\Delta$ pbp1b pbp2a) and IU5078 ( $\triangle$ pbp1b pbp1a) cells were grown in Becton-Dickinson brain heart infusion (BHI) broth at $37{ }^{\circ} \mathrm{C}$ in an atmosphere of $5 \% \mathrm{CO}_{2}$ to $\mathrm{OD}_{620} 0.2-0.4$. Cells from 1 $\mathrm{mL}$ of culture were centrifuged at $16,100 \times g$ for $2 \mathrm{~min}$ at RT and washed with PBS $(\mathrm{pH}$ 7.4). The cells were resuspended in $50 \mu \mathrm{L}$ of PBS containing $10 \mu \mathrm{g} \mathrm{mL}^{-1}$ of Ceph C-T or 5 $\mu \mathrm{g} \mathrm{mL}^{-1}$ of Boc-FL (Molecular Probes). After incubation for $30 \mathrm{~min}$ with Ceph C-T or 10 min with Boc-FL at RT, the cells were washed and resuspended in $100 \mu \mathrm{L}$ of PBS containing $1 \mathrm{mg} \mathrm{mL}^{-1}$ of lysozyme and $20 \mu \mathrm{g} \mathrm{mL}^{-1}$ of mutanolysin. The cells were incubated for $30 \mathrm{~min}$ at $37^{\circ} \mathrm{C}$ and then lysed by Branson Sonifier 250 (power setting 3, 30\% duty cycle for $5 \times 6 \mathrm{~s}$ intervals). The membrane proteome was isolated by centrifugation (Eppendorf Centrifuge 5424) at 16,100 $\times \mathrm{g}(20 \mathrm{~min}), 4^{\circ} \mathrm{C}$. Membrane proteome was resuspended by adding $100 \mu \mathrm{L}$ of lysis buffer (1\% SDS, $0.1 \%$ Triton X-100 in PBS) and protein concentration was determined by NanoDrop 1000 Spectrophotometer. Proteome sample was diluted to $2.5 \mathrm{mg} \mathrm{mL}^{-1}$ in lysis buffer. Following the addition of $17 \mu \mathrm{L}$ of $4 \times$ SDS-PAGE loading buffer to $51 \mu \mathrm{L}$ of proteome, the sample was heated $5 \mathrm{~min}$ at $90-95^{\circ} \mathrm{C}$, cooled to RT, run on a $10 \%$ SDS-PAGE and labeled proteins were visualized in gel using a Typhoon 9210 gel scanner (Amersham Biosciences). All gel images were analyzed using ImageJ software (NIH).

\section{Fluorescence imaging of B. subtilis and S. pneumoniae PBPs labeled with Ceph C-F, Ceph C-T and Boc-FL}

B. subtilis PY79 cells were grown in $\mathrm{LB}$ broth at $37^{\circ} \mathrm{C}$ to $\mathrm{OD}_{600} 0.4-0.5$. Cells from $1 \mathrm{~mL}$ of culture were harvested by centrifugation and washed with PBS. Cells were resuspended in $50 \mu \mathrm{L}$ of PBS containing $10 \mu \mathrm{g} \mathrm{mL}^{-1}$ of Ceph C probes or $5 \mu \mathrm{g} \mathrm{mL} \mathrm{m}^{-1}$ of Boc-FL. After incubation with Ceph $\mathrm{C}$ probes for $30 \mathrm{~min}$ or Boc-FL for $10 \mathrm{~min}$ at RT, the cells were washed to remove excess probe and resuspended in $50 \mu \mathrm{L}$ of PBS containing $10 \mu \mathrm{g} \mathrm{mL}-1$ of FM-4-64 or TMA-DPH (Molecular Probes). Following 2 min incubation at RT, the cells were washed and resuspended in $50 \mu \mathrm{L}$ of PBS. For fluorescence imaging, $5 \mu \mathrm{L}$ of cell suspension was spotted onto a clean slide and covered with a poly-L-lysine treated cover slip. Cells were also labeled in LB broth and imaged using $2 \%$ agarose pad and plain cover slips. The resulting images were identical (data not shown). 
S. pneumoniae IU1945 cells were grown in Becton-Dickinson brain heart infusion (BHI) broth at $37{ }^{\circ} \mathrm{C}$ in an atmosphere of $5 \% \mathrm{CO}_{2}$ to $\mathrm{OD}_{620} 0.2-0.4$. Cells from $1 \mathrm{~mL}$ of culture were centrifuged at $16,100 \times \mathrm{g}$ for $2 \mathrm{~min}$ at RT and washed with PBS (pH 7.4). The cells were labeled with Ceph C-T or Boc-FL and prepared for imaging as described above. Cells were also labeled as above but instead in BHI broth and covered with plain cover slips. The resulting images were identical (data not shown).

Cells were observed with either a Nikon 80i microscope equipped with an Excite 120 metal halide lamp or a Nikon E-400 epifluorescence phase-contrast microscope equipped with a mercury lamp with a $100 \times$ Nikon Plan Apo oil-immersion objective (numerical aperture, 1.40), using a C-FL HYQ FITC Filter Cube (FITC, excitation filter $460-500 \mathrm{~nm}$, barrier filter 515-550 nm) for Ceph C-F and Boc--FL, a C-FL HYQ Texas Red Filter Cube (excitation filter 532-587 nm, barrier filter $>590 \mathrm{~nm}$ ) for Ceph C-T and FM-4-64, and an UV-2E/C DAPI Filter Cube (excitation filter $340-380 \mathrm{~nm}$, barrier filter $435-485 \mathrm{~nm}$ ) for TMA-DPH. Images were captured using a CoolSNAP HQ ${ }^{2}$ charge-coupled device (CCD) camera (Photometrics) and processed with either Metamorph software (Molecular Devices) or NIS-Elements AR imaging software (Nikon).

\section{Supplementary Material}

Refer to Web version on PubMed Central for supplementary material.

\section{Acknowledgments}

We thank C. Kao for use of an ultracentrifuge, Indiana University Physical Biochemistry Instrumentation Facility for use of a fluorescence gel scanner, Indiana University Proteomics Facility for use of a LCQ-Deca XP Plus ion trap mass spectrometer and R. Arnold for assistance with mass spectrometry analysis. We also thank the Indiana University Light Microscopy Imaging Center (OMX supported by NIH S10RR028697-01) and J. Powers, S. Guttenplan and S. Shaw for helpful discussions. This work was supported by NIH R00GM82983 (E.E.C.), NIH DP2OD008592 (E.E.C.), NIH GM093030 (D.B.K.), NIH AI095814 (M.E.W.), funds from the Indiana University Bloomington METACyt Initiative, funded in part by a major grant from the Lilly Endowment (M.E.W.), a Pew Biomedical Scholar Award (E.E.C.), an NIH training grant T32GM007757 (R.A.C. and L.M.C) and Indiana University-Bloomington, Department of Chemistry.

\section{REFERENCES}

1. Vollmer W, Blanot D, de Pedro MA. Peptidoglycan structure and architecture. FEMS Microbiol Rev. 2008; 32:149-167. [PubMed: 18194336]

2. Sauvage E, Kerff F, Terrak M, Ayala JA, Charlier P. The penicillin-binding proteins: structure and role in peptidoglycan biosynthesis. FEMS Microbiol Rev. 2008; 32:556-556.

3. Rowley D, Cooper PD, Roberts PW. The site of action of penicillin. Biochem J. 1950; 46:157-161. [PubMed: 16748652]

4. Blumberg PM, Strominger JL. Isolation by covalent affinity chromatography of the penicillinbinding components from membranes of Bacillus subtilis. Proc Natl Acad Sci U S A. 1972; 69:3751-3755. [PubMed: 4630162]

5. McPherson DC, Driks A, Popham DL. Isolation by covalent affinity chromatography of the penicillin-binding components from membranes of Bacillus subtilis. J. Bacteriol. 2001; 183:60466053. [PubMed: 11567005]

6. Clatworthy AE, Pierson E, Hung DT. Targeting virulence: a new paradigm for antimicrobial therapy. Nat Chem Biol. 2007; 3:541-548. [PubMed: 17710100]

7. Fisher JF, Meroueh SO, Mobashery S. Bacterial resistance to $\beta$-lactam antibiotics: Compelling opotunism, compelling opportunities. Chem. Rev. 2005; 105:395-424. [PubMed: 15700950]

8. Falconer SB, Czarny TL, Brown ED. Antibiotics as probes of biological complexity. Nat. Chem. Biol. 2011; 7:415-423. [PubMed: 21685879] 
9. Böttcher T, Sieber SA. $\beta$-Lactams and $\beta$-lactones as activity-based probes in chemical biology. Med. Chem. Commun. 2012; 3:408-417.

10. Spratt BG, Pardee AB. Penicillin-binding proteins and cell shape in E. coli. Nature. 1975; 254:516-517. [PubMed: 1091862]

11. Tsien RY. The green fluorescent protein. Annu Rev Biochem. 1998; 67:509-544. [PubMed: 9759496]

12. Scheffers DJ, Jones LJF, Errington J. Several distinct localization patterns for penicillin-binding proteins in Bacillus subtilis. Mol Microbiol. 2004; 51:749-764. [PubMed: 14731276]

13. Foss MH, Eun Y-J, Weibel DB. Chemical-biological studies of subcellular organization in bacteria. Biochemistry. 2011; 50:7719-7734. [PubMed: 21823588]

14. Daniel RA, Errington J. Control of cell morphogenesis in bacteria: Two distinct ways to make a rod-shaped cell. Cell. 2003; 113:767-776. [PubMed: 12809607]

15. Tiyanont K, Doan T, Lazarus MB, Fang X, Rudner DZ, Walker S. Imaging peptidoglycan biosynthesis in Bacillus subtilis with fluorescent antibiotics. Proc Natl Acad Sci U S A. 2006; 103:11033-11038. [PubMed: 16832063]

16. Zhao G, Meier TI, Kahl SD, Gee KR, Blaszczak LC. BOCILLIN FL, a sensitive and commercially available reagent for detection of penicillin-binding proteins. Antimicrob Agents Chemother. 1999; 43:1124-1128. [PubMed: 10223924]

17. Lakaye B, Damblon C, Jamin M, Galleni M, Lepage S, Joris B, Marchand-Brynaert J, Frydrych C, Frere J-M. Synthesis, purification and kinetic properties of fluorescein-labelled penicillins. Biochem. J. 1994; 300:141-145. [PubMed: 8198525]

18. Liu Y, Patricelli MP, Cravatt BF. Activity-based protein profiling: the serine hydrolases. Proc Natl Acad Sci U S A. 1999; 96:14694-14699. [PubMed: 10611275]

19. Speers AE, Cravatt BF. Profiling enzyme activities in vivo using click chemistry methods. Chem Biol. 2004; 11:535-546. [PubMed: 15123248]

20. Staub I, Sieber SA. Beta-lactams as selective chemical probes for the in vivo labeling of bacterial enzymes involved in cell wall biosynthesis, antibiotic resistance, and virulence. J Am Chem Soc. 2008; 130:13400-13409. [PubMed: 18781750]

21. Curtis NAC, Orr D, Ross GW, Boulton MG. Affinities of penicillins and cephalosporins for the penicillin-binding proteins of Escherichia coli K-12 and their antibacterial activity. Antimicrob Agents Chemother. 1979; 16:533-539. [PubMed: 393164]

22. Kleppe G, Strominger JL. Studies of the high molecular weight penicillin-binding proteins of Bacillus subtilis. J Biol Chem. 1979; 254:4856-4862. [PubMed: 108285]

23. Sadhu KK, Mizukami S, Hori Y, Kikucki K. Switching modulation for protein labeling with activatable fluorescent probes. ChemBioChem. 2011; 12:1299-1308. [PubMed: 21630408]

24. Popham DL, Setlow P. Phenotypes of Bacillus subtilis mutants lacking multiple class A highmolecular-weight penicillin-binding proteins. J Bacteriol. 1996; 178:2079-2085. [PubMed: 8606187]

25. Pederson LB, Angert ER, Setlow P. Septal localization of penicillin-binding protein 1 in Bacillus subtilis. J. Bacteriol. 1999; 181:3201-3211. [PubMed: 10322023]

26. Patrick JE, Kearns DB. MinJ (YvjD) is a topological determinant of cell division in Bacillus subtiis. Mol. Microbiol. 2008; 70:1166-1179. [PubMed: 18976281]

27. Garner EC, Bernard R, Wang W, Zhuang X, Rudner DZ, Mitchison T. Coupled, circumferential motions of the cell wall synthesis machinery and MreB filaments in B. subtilis. Science. 2011; 333:222-225. [PubMed: 21636745]

28. Domínquez-Escobar J, Chastenet A, Crevenna AH, Fromion V, Wedlich-Söldner R, CarballidoLópez. Processive movement of MreB-associated cell wall biosynthetic complexes in bacteria. Science. 2011; 333:225-228. [PubMed: 21636744]

29. Typas A, Banzhaf M, van den Berg van Saparoea B, Verheul J, Biboy J, Nichols RJ, Zietek M, Beilharz K, Kannenberg K, von Rechenberg M, Breukink E, den Blaauwen T, Gross CA, Vollmer W. Regulation of peptidoglycan synthesis by outer-membrane proteins. Cell. 2010; 143:10971109. [PubMed: 21183073] 
30. Paradis-Bleau C, Markovski M, Uehara T, Lupoli TJ, Walker S, Kahne DE, Bernhardt TG. Lipoprotein cofactors located in the outer membrane activate cell wall polymerases. Cell. 2010; 143:1110-1120. [PubMed: 21183074]

31. Lanie JA, Ng WL, Kazmierczak KM, Andrzejewski TM, Davidsen TM, Wayne KJ, Tettelin H, Glass JI, Winkler ME. Genome sequence of Avery's virulent serotype 2 strain D39 of Streptococcus pneumoniae and comparison with that of unencapsulated laboratory strain R6. J. Bacteriol. 2007; 189:38-51. [PubMed: 17041037]

32. Williamson R, Hakenbeck R, Tomasz A. In vivo interaction of beta-lactam antibiotics with the penicillin-binding proteins of Streptococcus pneumoniae. Antimicrob Agents Chemother. 1980; 18:629-637. [PubMed: 7447421]

33. Zapun A, Vernet T, Pinho MG. The different shapes of cocci. FEMS Microbiol. Rev. 2008; 32:345-360. [PubMed: 18266741]

34. Land AD, Winkler ME. The requirement for pneumococcal MreC and MreD is relieved by inactivation of the gene encoding PBP1a. J. Bacteriol. 2011; 193:4166-4179. [PubMed: 21685290]

35. Sham LT, Tsui HC, Land AD, Barendt SM, Winkler ME. Recent advances in pneumococcal peptidoglycan biosynthesis suggest new vaccine and antimicrobial targets. Curr. Opin. Microbiol. 2012; 15:194-203. [PubMed: 22280885]

36. Perez-Nunez D, Briandet R, David B, Gautier C, Renault P, Hallet B, Hols P, Carballido-Lopez R, Guedon E. A new morphogenesis pathway in bacteria: unbalanced activity of cell wall synthesis machineries leads to coccus-to-rod transition and filamentation in ovococci. Mol. Microbiol. 2011; 79:759-771. [PubMed: 21255117]

37. Morlot C, Noirclerc-Savoye M, Zapun A, Dideberg O, Vernet T. The D,D-carboxypeptidase PBP3 organizes the division process of Streptococcus pneumoniae. Mol. Microbiol. 2004; 51:16411648. [PubMed: 15009891]

38. Barendt SM, Sham LT, Winkler ME. Characterization of Mutants Deficient in the L,DCarboxypeptidase (DacB) and WalRK (VicRK) Regulon, Involved in Peptidoglycan Maturation of Streptococcus pneumoniae Serotype 2 Strain D39. J. Bacteriol. 2011; 193:2290-2300. [PubMed: 21378199] 


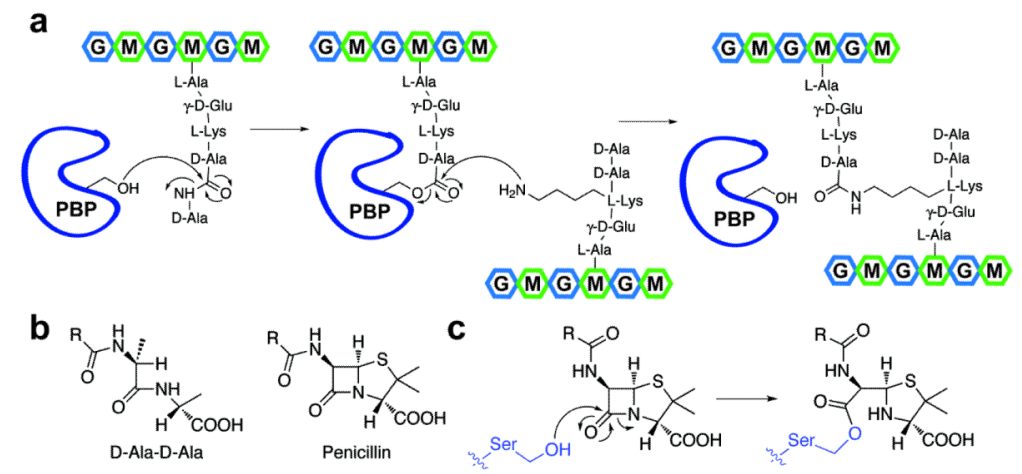

Figure 1.

Comparison of the transpeptidation reaction performed by penicillin-binding proteins (PBPs) and their inactivation by the $\beta$-lactam antibiotic, penicillin. (a) PBPs catalyze transpeptidation by cleavage of the terminal D-Ala residue of the stem peptide resulting in formation of an acyl-enzyme intermediate. In most Gram-positive bacteria, this ester is subsequently attacked by the lysine residue of a neighboring stem peptide to crosslink the chains. $\mathrm{M}=N$-acetylmuramic acid, $\mathrm{G}=N$-acetylglucosamine. In $B$. subtilis, L-Lys is replaced with meso-diaminopimelic acid. (b) Penicillin is a structural mimetic of the natural substrate for PBPs. (c) The active site serine in PBPs attacks the highly strained $\beta$-lactam ring resulting in opening of the lactam. This reaction leads to irreversible covalent modification of the PBP. 
a

$\mathrm{R}=$

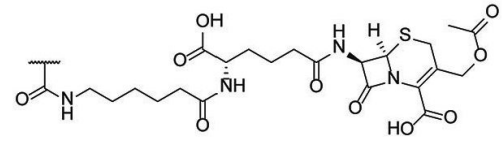

Ho
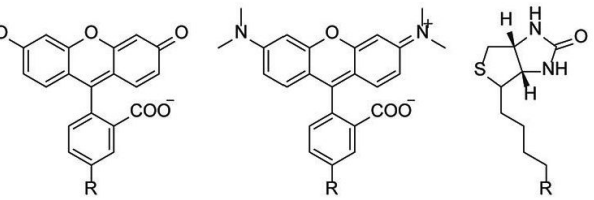

Ceph C-F

Ceph C-T

Ceph C-B

b
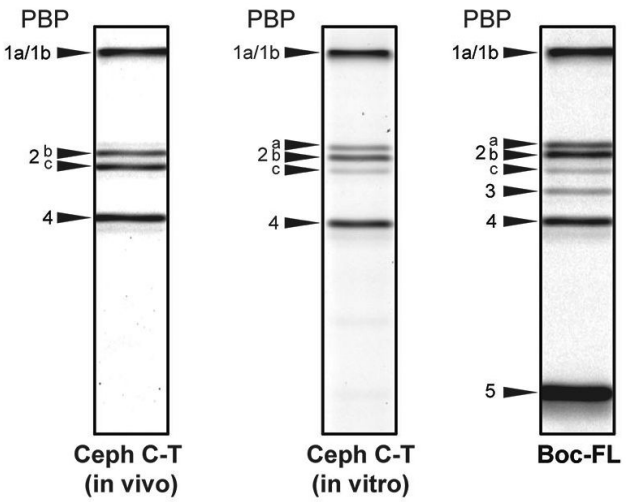

Figure 2.

Structures of the cephalosporin C-based probes and utilization in gel-based analysis in comparison to BOCILLIN-FL. (a) Ceph $\mathrm{C}$ probes were designed with three reporter tags. Ceph C core (R), TAMRA (Ceph C-T), fluorescein (Ceph C-F) and biotin (Ceph C-B). (b) Gel-based analysis of the PBP profiles of B. subtilis PY79 cells that are labeled with Ceph $\mathrm{C}-\mathrm{T}$ (in vivo or in vitro labeling of membrane proteome) or Boc-FL (in vivo labeling shown, in vitro profile was similar). Several bands show differential labeling by Ceph C-T when this compound is applied to live cells versus membrane proteome. Whereas Boc-FL labels all active PBPs in the sample, Ceph $\mathrm{C}$ labels only four PBPs when utilized in in vivo experiments. These proteins were subsequently identified as PBPs $1 \mathrm{a} / 1 \mathrm{~b}, 2 \mathrm{~b}, 2 \mathrm{c}$ and 4. 


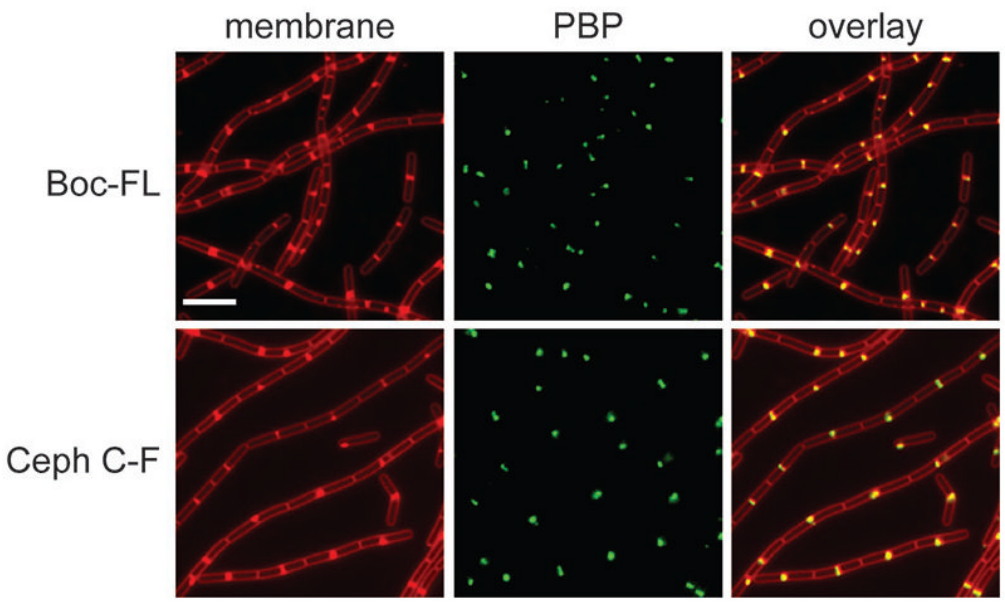

Figure 3.

Localization of Ceph C-F and Boc-FL labeled PBPs in B. subtilis PY79. Cells were stained with either Ceph C-F or Boc-FL and then subjected to a membrane dye (FM-4-64). The two probes yielded similar staining patterns with the PBPs labeled by Ceph C-F and Boc-FL both being localized on every other division septa. Scale bar, $2 \mu \mathrm{m}$. 


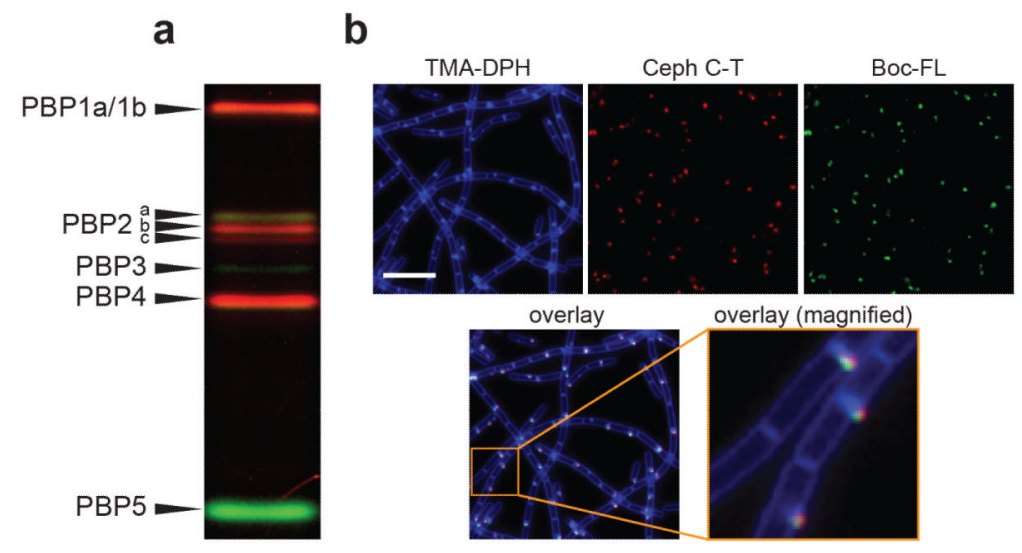

\section{Figure 4.}

Imaging of $B$. subtilis PBPs after dual labeling with Ceph C-T (red) and Boc-FL (green) in vivo as visualized with gel-based and wide-field fluorescence microscopy methods. (a) Labeling was performed first with Ceph C-T (30 min) followed by treatment with by BocFL (10 min). The selectivity profile observed when labeling the cells with only Ceph C-T was preserved (PBPs 1a/b, 2b, 2c and 4). (b) Wide-field microscopy images of dual labeled cells show almost complete co-staining with Ceph C-T and Boc-FL. 1-(4-

trimethylammoniumphenyl)-6-phenyl-1,3,5-hexatriene p-toluenesulfonate (TMA-DPH) was used to dye the entire membrane (blue). Scale bars, $2 \mu \mathrm{m}$. 
a
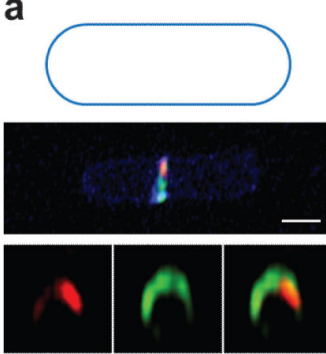

b
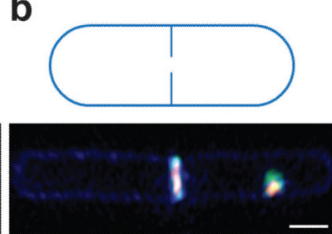

c

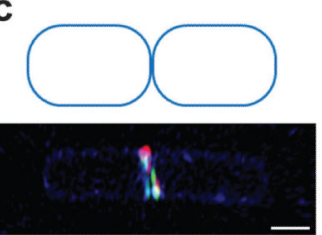

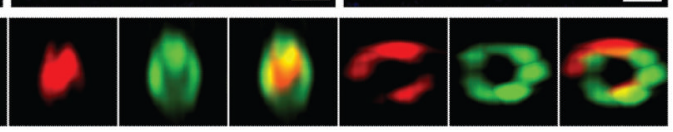

Figure 5.

Imaging of B. subtilis PBPs after dual labeling with Ceph C-T (red) and Boc-FL (green) in vivo as visualized with 3D-SIM super-resolution microscope. Labeling was performed first with Ceph C-T (30 $\mathrm{min})$ followed by treatment with by Boc-FL (10 min). TMA-DPH was used to stain the entire membrane (blue). Images demonstrate that Ceph C-T and Boc-FL labeling at the division septa are not co-localized indicating that the PBPs targeted by the probes are found in different regions. Top images are of the whole cell while bottom panels show an end on view of the divisional septa. (a) Cells with the earliest divisional septa showed crescent-shaped fluorescent labeling with asymmetric intensity. (b) Cells marked by invaginations of the membrane show PBP localization as a disk. (c) Following division, crescent shapes were retained at the pole in each daughter cell (c). Scale bars, $1 \mu \mathrm{m}$. 


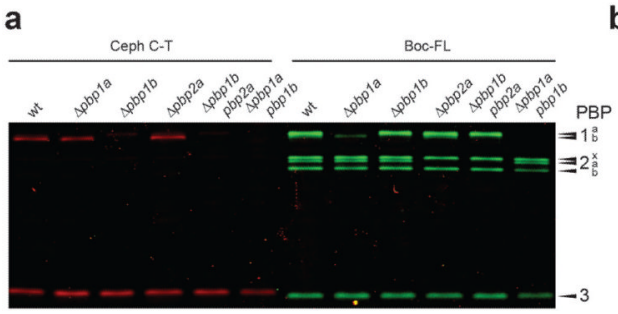

b

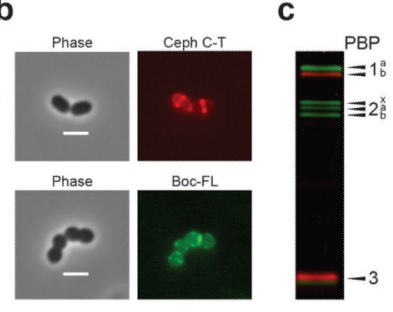

Figure 6.

PBP labeling of $S$. pneumoniae with Ceph C-T (red) or Boc-FL (green). (a) Gel-based analysis of $S$. pneumoniae PBPs labeled with Ceph C-T or Boc-FL. Mutant strains were used to assign the proteins labeled with Ceph C-T. This probe labels PBP1a (faint), $1 \mathrm{~b}$ and 3. Boc-FL labels all active PBPs including PBPs $2 \mathrm{a}, 2 \mathrm{~b}$ and $2 \mathrm{x}$, which are not labeled by Ceph C-T. (b) Staining patterns of Ceph-T and Boc-FL labeled PBPs in live cells as detected by wide-field fluorescence microscopy. Scale bar, $2 \mu \mathrm{m}$. (c) Gel-based analysis of $S$.

pneumoniae PBPs labeled first with Ceph C-T (30 min) followed by treatment with by BocFL (10 min). The weak labeling of PBP1a by Ceph C-T is outcompeted with Boc-FL. In addition, PBP3 is labeled by both probes (two bands are the result of slight variation in migration of the two labeled proteins). 

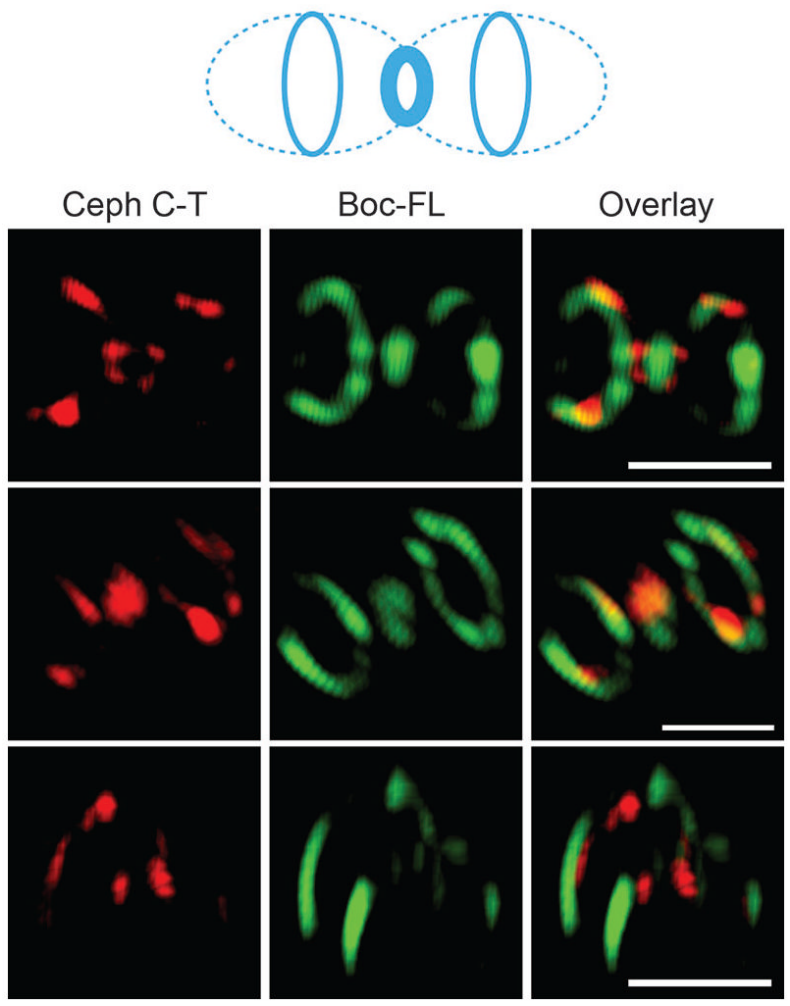

Figure 7.

Super-resolution (3D-SIM) images of $S$. pneumoniae IU1945 PBPs after dual labeling with Ceph C-T (red) and Boc-FL (green) in vivo. Both dyes were seen in the septal and equatorial regions but little co-localization of the two PBP subsets was observed indicating differential distribution. Scale bar, $1 \mu \mathrm{m}$. 